\title{
Bisphosphonate-induced atypical subtrochanteric femoral fracture
}

\author{
Raju Vaishya, ${ }^{1}$ Abhishek Vaish, ${ }^{2}$ Arshad Nadeem ${ }^{3}$
}

${ }^{1}$ Department of Orthopaedic and Joint Replacement Surgery, Indraprastha Apollo Hospitals, New Delhi, India ${ }^{2}$ Department of Orthopaedics, Sancheti Hospital, Pune, Maharashtra, India ${ }^{3}$ Department of Physiotherapy, Healing Touch Clinic, New Delhi, India

\section{Correspondence to} Professor Raju Vaishya, raju.vaishya@gmail.com

\section{SUMMARY}

The use of bisphosphonates (BPs) is universally accepted in the management of osteoporosis. However, a small percentage of patients have been recognised to develop atypical subtrochanteric fractures of the femur with the prolonged use of BPs. We report a rare case of bilateral insufficiency lesions in the proximal femora, where a major subtrochanteric fracture developed with a minor fall. This was successfully treated with internal fixation using proximal femoral nail.

\section{BACKGROUND}

Presently, bisphosphonates (BPs) are the mainstay of therapy of osteoporosis. However, there are some concerns about the long-term use of these drugs, as they suppress bone remodelling, leading to unusual femoral fractures. ${ }^{1}$ It has been suggested that the prolonged effect on bone remodelling leads to the accumulation of microfractures and weakening of bone. Hence, its prolonged use may be associated with insufficiency fractures of the femoral shaft, which commonly present with prodromal thigh pain. These fractures are characteristically atypical and were neither seen or described before BPs became available for use. ${ }^{2}$ These fractures thus represent a new disease entity associated with the use of BPs.

\section{CASE PRESENTATION}

A 63-year-old peasant women presented with a history of gradually increasing bilateral thigh and groin pain $(\mathrm{L}>\mathrm{R})$ for the past 1 year. She had been finding it difficult to do her routine walk in the house and elsewhere, to the extent that she had become almost bed ridden and went into a severe depression. There had been an associated generalised weakness in the body. There was no history of trauma, fever, weight loss, etc.

She was a vegetarian by habit and was under treatment for multiple medical problems such as bronchial asthma, hypertension, hypothyroidism and osteoporosis. Her osteoporosis was diagnosed on routine dual energy X-ray absorptiometry (DEXA) scan about 4 years ago and she was put on weekly sodium alendronate $(70 \mathrm{mg}$ weekly) for about 3 years, along with calcium supplements.

\section{INVESTIGATIONS}

Her pelvis $\mathrm{X}$-ray anteroposterior (AP) view showed focal eccentric sclerosis in the lateral cortex of the proximal shaft of both femora with a convex bulge of the cortical margin of the bone (figure 1). There was associated generalised loss of density of both proximal femora. Her DEXA scan confirmed osteoporosis with $\mathrm{T}$ scores of -3.1 (spine) and -2.4 (hip). All the main metabolic laboratory findings for example, serum vitamin D3, calcium, alkaline phosphatase and serum parathyroid hormone, etc were within normal limits.

\section{DIFFERENTIAL DIAGNOSIS}

- Insufficiency fractures of osteomalacia

- Osteoid osteoma

- BP-induced insufficiency fractures

- Non-traumatic stress fracture

\section{TREATMENT}

Her alendronate therapy was stopped and she was put on daily injections of teriparatide $(20 \mu \mathrm{g}$ subcutaneous). She started responding dramatically to the treatment within 3 weeks. But after 2 months of therapy she had a minor slip off the stairs in a golf course and sustained a major subtrochanteric fracture of the left femur (figure 2). This was fixed with a proximal femoral nail (PFN II), under spinal anaesthesia.

\section{OUTCOME AND FOLLOW-UP}

The patient was mobilised non-weight bearing for 2 months with walking frame and then gradually increasing weight bearing was permitted. The fracture was slow to heal and only after 18 months of the fracture fixation, it showed complete union (figure 3).

\section{DISCUSSION}

Osteoporosis is often associated with significant morbidity and mortality, especially in elderly patients. BPs are the most important class of antiresorptive agents that are available to treat diseases characterised by osteoclast-mediated bone resorption such as osteoporosis, Paget disease and

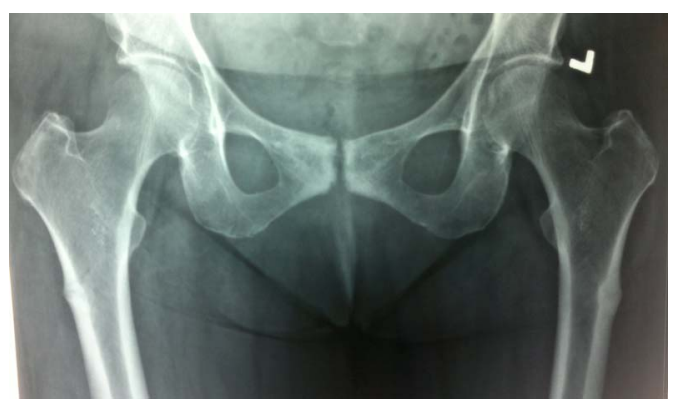

Figure 1 Bilateral insufficiency lesions in proximal femora. 


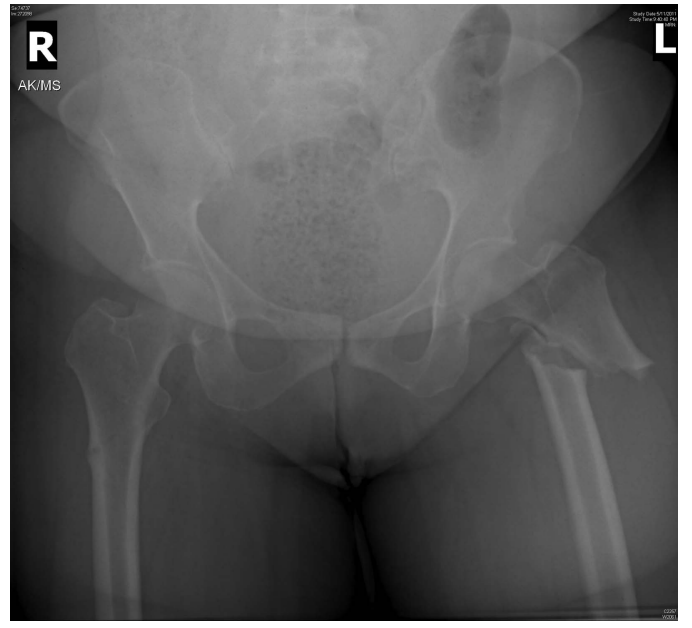

Figure 2 Atypical subtrochanteric fracture of left femur.

tumour-associated bone diseases. ${ }^{3}$ BPs have been proven beyond doubt in several large published studies to reduce the risk of hip fracture in osteoporosis.

Among older women, treatment with a BPs for more than 5 years has been shown to be associated with an increased risk of subtrochanteric or femoral shaft fractures. ${ }^{1}$ Although there was a high prevalence of current BPs among patients with atypical fractures, the absolute risk was small. ${ }^{4}$ The age-adjusted incidence rates for an atypical fracture were 1.78/100 000/year (95\% CI 1.5 to 2.0 ) with exposure from 0.1 to 1.9 years, and increased to $113.1 / 100000$ year (95\% CI 69.3 to 156.8 ) with exposure from 8 to 9.9 years. $^{5}$

These atypical fractures have special characteristics. They are usually transverse, affecting the proximal third of the femoral shaft. They occur after minor or no trauma, include a thickening of the lateral femoral cortex, a delayed consolidation time and prodromal symptoms. In this context, the risk/benefit ratio of

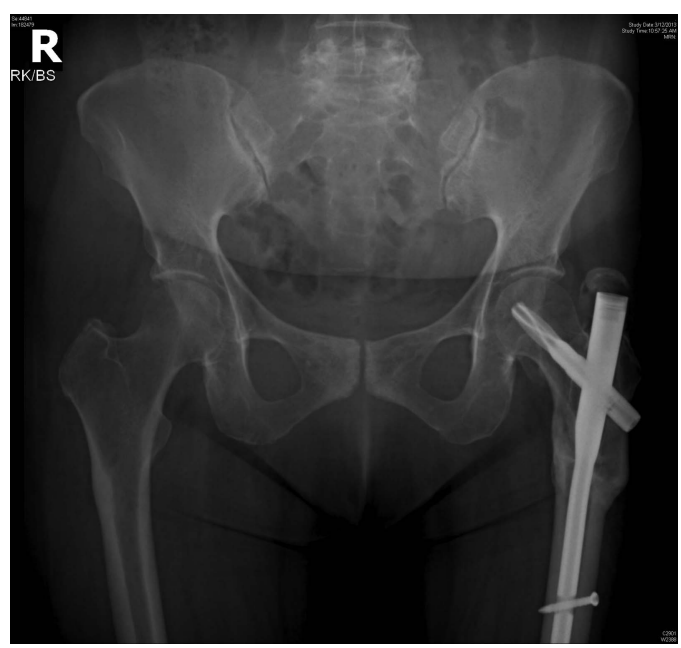

Figure 3 Healed subtrochanteric fracture after proximal femoral nail fixation.
BPs remains favourable if the indication is adequate. Pain or discomfort in the thigh in a patient receiving BPs should lead to radiological investigations in order to detect the possible occurrence of a stress fracture. ${ }^{6}$ A significantly greater proportion of patients with subtrochanteric/shaft fractures were found to be on long-term BPs than intertrochanteric/femoral neck fractures. BPs use was highly associated with a unique X-ray pattern. ${ }^{7}$

Apart from stopping BPs, the treatment of these atypical subtrochanteric fracture is surgical. They are best fixed using intramedullary (IM) locking nail such asPFN. Traditionally, IM nailing of femoral shaft fractures was reported to be a very successful surgical procedure, with 98-99\% healing rate and a very low complication rate. $^{8}$ Despite good fixation these atypical fractures take a much longer time than a similar post-traumatic fractures.

\section{Learning points}

- Bisphosphonates (BPs) are widely used for the treatment of osteoporosis, as they are proven agents to prevent hip and spine fractures.

- However, in small percentage of patients with its prolonged use insufficiency fractures of the femur especially in subtrochanteric region may occur.

- These atypical fractures are characteristically different than traumatic fractures and are very slow to unite.

- The treatment of choice for such fractures is surgical, with internal fixation by intramedullary nail such as proximal femoral nail.

- Prolonged use of BPs (for more than 3-5 years) must be discouraged to prevent these fractures.

Contributors All authors contributed in preparing the manuscript for submission. Competing interests None.

Patient consent Obtained.

Provenance and peer review Not commissioned; externally peer reviewed.

\section{REFERENCES}

1 Park-Wyllie LY, Mamdani MM, Juurlink DN, et al. Bisphosphonate use and the risk of subtrochanteric or femoral shaft fractures in older women. JAMA 2011;305:783-9.

2 Isaacs JD, Shidiak L, Harris IA, et al. Femoral insufficiency fractures associated with prolonged bisphosphonate therapy. Clin Orthop Relat Res 2010;468:3384-92.

3 Morris CD, Einhorn TA. BPs in orthopaedic surgery. J Bone Joint Surg Am 2005;87:1609-18.

4 Schilcher J, Michaëlsson K, Aspenberg P. Bisphosphonate use and atypical fractures of the femoral shaft. N Engl J Med 2011;364:1728-37.

5 Dell RM, Adams AL, Greene DF, et al. Incidence of atypical nontraumatic diaphyseal fractures of the femur. J Bone Miner Res 2012;27:2544-50.

6 Ing Lorenzinit K, Meier R, Suva D, et al. Atypical femoral fracture associated with the use of BPs, an adverse drug reaction not to be missed. Rev Med Suisse 2012;8:1238-42. [Article in French]

7 Lenart BA, Neviaser AS, Lyman S, et al. Association of low-energy femoral fractures with prolonged bisphosphonate use: a case control study. Osteoporos Int 2009;20:1353-62.

8 Tornetta P, Tiburzi D. Antegrade or retrograde reamed femoral nailing. J Bone Joint Surg B 2000;82:652-4. 
Copyright 2013 BMJ Publishing Group. All rights reserved. For permission to reuse any of this content visit http://group.bmj.com/group/rights-licensing/permissions.

BMJ Case Report Fellows may re-use this article for personal use and teaching without any further permission.

Become a Fellow of BMJ Case Reports today and you can:

- Submit as many cases as you like

- Enjoy fast sympathetic peer review and rapid publication of accepted articles

- Access all the published articles

- Re-use any of the published material for personal use and teaching without further permission

For information on Institutional Fellowships contact consortiasales@bmjgroup.com

Visit casereports.bmj.com for more articles like this and to become a Fellow 